\title{
Visit Frequency for Patients with Type-2 Diabetes Varies More by Organization than by Glucose Control: a Retrospective Cohort Study
}

\author{
M. Brooke Herndon, MD MS' , Barbara Gladders, $M S^{2}$, Gavin Welch, $P h D^{3}$, \\ Sanjeev Mehta, MD MPH', Thomas Belnap, MS , and Nancy E. Morden, MD MPH \\ ${ }^{1}$ Section of General Internal Medicine, Dartmouth Hitchcock Medical Center and the Geisel School of Medicine, Lebanon, NH, USA; ${ }^{2} \mathrm{Heart} \&$ \\ Vascular Center at Dartmouth Hitchcock Medical Center, Lebanon, USA; ${ }^{3}$ Quality and Safety Department, Maine Medical Center, Portland, USA; \\ ${ }^{4}$ Joslin Diabetes Center, Boston, USA; ${ }^{5}$ Intermountain Healthcare, Salt Lake City, USA; ${ }^{6}$ The Dartmouth Institute for Health Policy \& Clinical Practice, \\ Lebanon, USA.
}

KEY WORDS: chronic care; organization and delivery of care; primary care; managed care-quality.

$\mathrm{J}$ Gen Intern Med 35(2):599=602

DOI: $10.1007 / \mathrm{s} 11606-019-05422-8$

(c) Society of General Internal Medicine 2019

\section{INTRODUCTION}

A growing literature raises concerns about the frequency and timing of ambulatory visits among patients with chronic conditions. ${ }^{1-5}$ However, to date, few studies have investigated the distribution of ambulatory visits for chronic conditions, especially outside of the Medicareinsured population.

We conducted a retrospective cohort study of 103,220 adults with type- 2 diabetes receiving care at nine healthcare organizations within the High Value Healthcare Collaborative (HVHC) between October 2012 and September 2014. ${ }^{6}$ We measured the association between diabetes control and ambulatory visit frequency.

\section{METHODS}

HVHC organizations submit patient-level clinical and administrative data biannually, including demographics, medical conditions (ICD-9-CM codes), vital signs, laboratory results, ambulatory encounters, hospital admissions, and clinician credentials. We studied data from the 9 of 14 HVHC organizations that had complete data: Baylor Health Care System, Denver Health, Hawaii Pacific Health, Intermountain Healthcare, Mayo Clinic Rochester, Providence Health \& Services, Sinai Health

Published online December 2, 2019
System Chicago, Scott \& White Healthcare, and Virginia Mason Medical Center.

Within the study period, we defined organizationspecific cohorts of adults with type- 2 diabetes as those (a) age 18 years or older with at least two visits with a type-2 diabetes diagnostic code during any 12-month interval, (b) at least one primary care provider visit, and (c) a valid glycosylated hemoglobin (A1c) value at least 12 months prior to the end of the study period. Primary care was defined as General Practice, Family Medicine, General Internal Medicine, or Geriatrics.

We determined organization-level mean total ambulatory primary care and endocrinology visits per person during the 12 months following the index A1c measurement. Our independent variable was the patient-level index A1c value, categorized by level of glucose control.

To explore the relationship between index A1c level and visit intensity, we generated system-specific models, treating each organization as an expected effect modifier. The pre-specified primary outcome, mean annual ambulatory visits per person, was modeled as a negative binomial distribution using a generalized linear model. Covariates included age, sex, race, and low socioeconomic status (primary payer of Medicaid, County Medically Indigent Service, Charity, or Self-Pay). We estimated confidence intervals using the percentile bootstrap method with 5,000 repetitions.

\section{RESULTS}

Patient characteristics and unadjusted visit rates are shown in Table 1. Organization-specific cohort size ranged from 693 at Sinai Health System to 30,973 at Baylor Health Care System. Mayo Clinic had the lowest 
Table 1 Patient Characteristics and Unadjusted 12-Month Visit Rate by Organization

\begin{tabular}{|c|c|c|c|c|c|c|c|c|c|c|}
\hline \multirow[t]{3}{*}{ Characteristic } & \multicolumn{10}{|c|}{ HVHC organization } \\
\hline & \multirow{2}{*}{$\begin{array}{l}\text { Baylor } \\
n \\
(30973)\end{array}$} & \multirow{2}{*}{$\frac{\text { Denver }}{n(7301)}$} & \multirow{2}{*}{$\frac{\text { Hawaii }}{n(8707)}$} & \multirow{2}{*}{$\begin{array}{l}\text { Intmtn } \\
n \\
(25236)\end{array}$} & \multirow{2}{*}{$\frac{\text { Mayo }}{n(2540)}$} & \multirow{2}{*}{$\begin{array}{l}\text { Provid } \\
n \\
(\mathbf{1 7 5 8 3 )}\end{array}$} & \multirow{2}{*}{$\frac{\text { Sinai }}{n(693)}$} & \multirow{2}{*}{$\frac{S W}{n(5601)}$} & \multirow{2}{*}{$\frac{\text { VMMC }}{n(4586)}$} & \multirow{2}{*}{$\begin{array}{l}\text { TOTAL } \\
n \\
(103220)\end{array}$} \\
\hline & & & & & & & & & & \\
\hline Means age (SD) & $\begin{array}{l}59.6 \\
(12.6)\end{array}$ & $\begin{array}{l}57.3 \\
(12.5)\end{array}$ & $\begin{array}{l}65.5 \\
(13.6)\end{array}$ & $\begin{array}{l}63.7 \\
(13.3)\end{array}$ & $\begin{array}{l}66.4 \\
(12.3)\end{array}$ & $\begin{array}{l}64.3 \\
(13.7)\end{array}$ & $\begin{array}{l}61 \\
(12.2)\end{array}$ & $\begin{array}{l}61.6 \\
(13.2)\end{array}$ & $\begin{array}{l}64.8 \\
(12.3)\end{array}$ & $\begin{array}{l}62.2 \\
(13.3)\end{array}$ \\
\hline \multicolumn{11}{|l|}{ Age group, \% } \\
\hline $18-24$ & 0.3 & 0.6 & 0.2 & 0.4 & 0.2 & 0.3 & 1.2 & 0.2 & 0.2 & 0.3 \\
\hline $25-34$ & 2.4 & 3.4 & 1.4 & 2.1 & 1.1 & 1.7 & 2.0 & 2.5 & 1.5 & 2.1 \\
\hline $35-44$ & 9.6 & 10.8 & 5.3 & 6.4 & 3.6 & 6.5 & 6.2 & 8.3 & 4.3 & 7.6 \\
\hline $45-54$ & 21.7 & 24.9 & 13.8 & 14.1 & 12.5 & 15.0 & 16.0 & 17.7 & 13.1 & 17.4 \\
\hline $55-64$ & 30.5 & 32.2 & 24.8 & 25.9 & 21.6 & 25.1 & 34.2 & 27.8 & 27.1 & 27.6 \\
\hline $65-74$ & 23.5 & 19.4 & 28.6 & 29.2 & 32.3 & 28.0 & 27.4 & 26.2 & 32.2 & 26.6 \\
\hline \multirow{2}{*}{\multicolumn{11}{|c|}{ Sex, \% }} \\
\hline & & & & & & & & & & \\
\hline Female & 49.7 & 60.0 & 50.2 & 48.7 & 42.5 & 52.8 & 61.6 & 54.8 & 45.2 & 50.7 \\
\hline \multicolumn{11}{|l|}{ Race, $\%$} \\
\hline Black & 15.2 & 18.4 & 1.0 & 0.9 & 1.7 & 4.0 & 56.0 & 12.6 & 7.3 & 8.3 \\
\hline White & 70.1 & 76.8 & 19.2 & 92.9 & 91.7 & 79.1 & 14.4 & 68.6 & 71.8 & 73.6 \\
\hline Other & 4.8 & 4.8 & 73.6 & 4.1 & 5.4 & 14.1 & 22.1 & 17.8 & 13.7 & 13.3 \\
\hline Unknown & 9.9 & 0.0 & 6.2 & 2.0 & 1.3 & 2.7 & 7.5 & 1.0 & 7.2 & 4.9 \\
\hline $\begin{array}{l}\text { Low socioeconomic } \\
\text { status, } \%\end{array}$ & 5.4 & 64.7 & 23.6 & 9.6 & 10.0 & 11.4 & 86.3 & 10.8 & 5.1 & 14.1 \\
\hline \multicolumn{11}{|l|}{ Index A1c, \% } \\
\hline Mean A1c (SD) & $7.5(1.8)$ & $8.1(1.9)$ & $7.4(1.6)$ & $7.4(1.7)$ & $7.3(1.5)$ & $8.1(2.2)$ & $7.5(1.5)$ & $7.5(1.7)$ & & \\
\hline$<6$ & 11.6 & 5.1 & 7.3 & 14.5 & 3.4 & 13.4 & 10.8 & 14.1 & 9.4 & 11.6 \\
\hline $6-6.9$ & 38.6 & 28.9 & 47.6 & 37.4 & 27.5 & 38.5 & 27.0 & 35.1 & 33.2 & 37.6 \\
\hline $7-7.9$ & 22.8 & 24.4 & 22.3 & 23.0 & 32.3 & 23.0 & 20.8 & 21.1 & 28.6 & 23.4 \\
\hline $8-8.9$ & 10.9 & 14.9 & 8.9 & 10.8 & 20.1 & 10.3 & 14.0 & 12.2 & 14.6 & 11.4 \\
\hline 9-9.9 & 6.2 & 10.1 & 5.3 & 5.7 & 7.9 & 5.9 & 8.7 & 6.8 & 7.0 & 6.3 \\
\hline $10-10.9$ & 3.8 & 6.6 & 3.6 & 3.3 & 4.8 & 3.5 & 7.4 & 5.0 & 3.5 & 3.9 \\
\hline $11+$ & 6.1 & 9.9 & 4.9 & 5.3 & 3.9 & 5.4 & 11.4 & 5.8 & 3.8 & 5.8 \\
\hline Annual visit rate & $4.6(2.6)$ & $4.6(2.9)$ & $5.4(3.1)$ & $4.4(2.9)$ & $2.0(1.4)$ & $4.5(3.0)$ & $5.2(3.2)$ & $4.6(2.8)$ & $5.1(4.0)$ & $4.6(2.9)$ \\
\hline
\end{tabular}

${ }^{ \pm}$Unadjusted mean number of primary care and endocrinology visits in 12 months following index Alc measurement. Source: High Value Healthcare Collaborative, 10/1/12-9/30/14 data submission

mean A1c at 7.3\% (SD 1.5), and Hawaii Pacific Health had the greatest proportion of patients with index A1c in excellent control $(55 \%$ A1c $<7.0 \%)$. Organizations with higher proportions of low SES patients had the highest mean A1c values, $8.1 \%$ at both Denver Health and Sinai Health System (SD 1.9 and 2.2 respectively). The unadjusted 12-month visit rate ranged from 2.0 (SD 1.4) at Mayo Clinic to 5.4 (SD 3.1) at Hawaii Pacific Health.

Figure 1 illustrates unadjusted and adjusted organization-level mean 12-month visit rate stratified by index A1c category. At Hawaii Pacific Health, patients in poor control $(10.0-10.9 \%)$ had, on average, 1.2 more visits per year than those in excellent control (6.0-6.9\%). Baylor Health Care System provided 0.6 more visits for patients in poor versus excellent control. For all other organizations, there was no significant difference in mean visit rates between patients with well-controlled vs. poorly controlled diabetes.

\section{DISCUSSION}

Consistent with prior literature on the general adult population, we found that visit frequency for patients with type 2 diabetes is not correlated with disease severity as assessed using Alc levels. There is substantial variation across organizations, but relatively little within organizations.

Our study is limited by our sample of nine health systems, and findings may not be generalizable. Further, we could not control for patient level factors such as social determinants of health or organizational factors that may have confounded our results.

To better understand the relationship between visit frequency and care value for patients with type 2 diabetes, future work should include both randomized controlled trials to evaluate optimal visit intervals for patients with diabetes at varying levels of glycemic control as well as comparative effectiveness analyses of strategies other than office visits to care for patients with chronic conditions. 


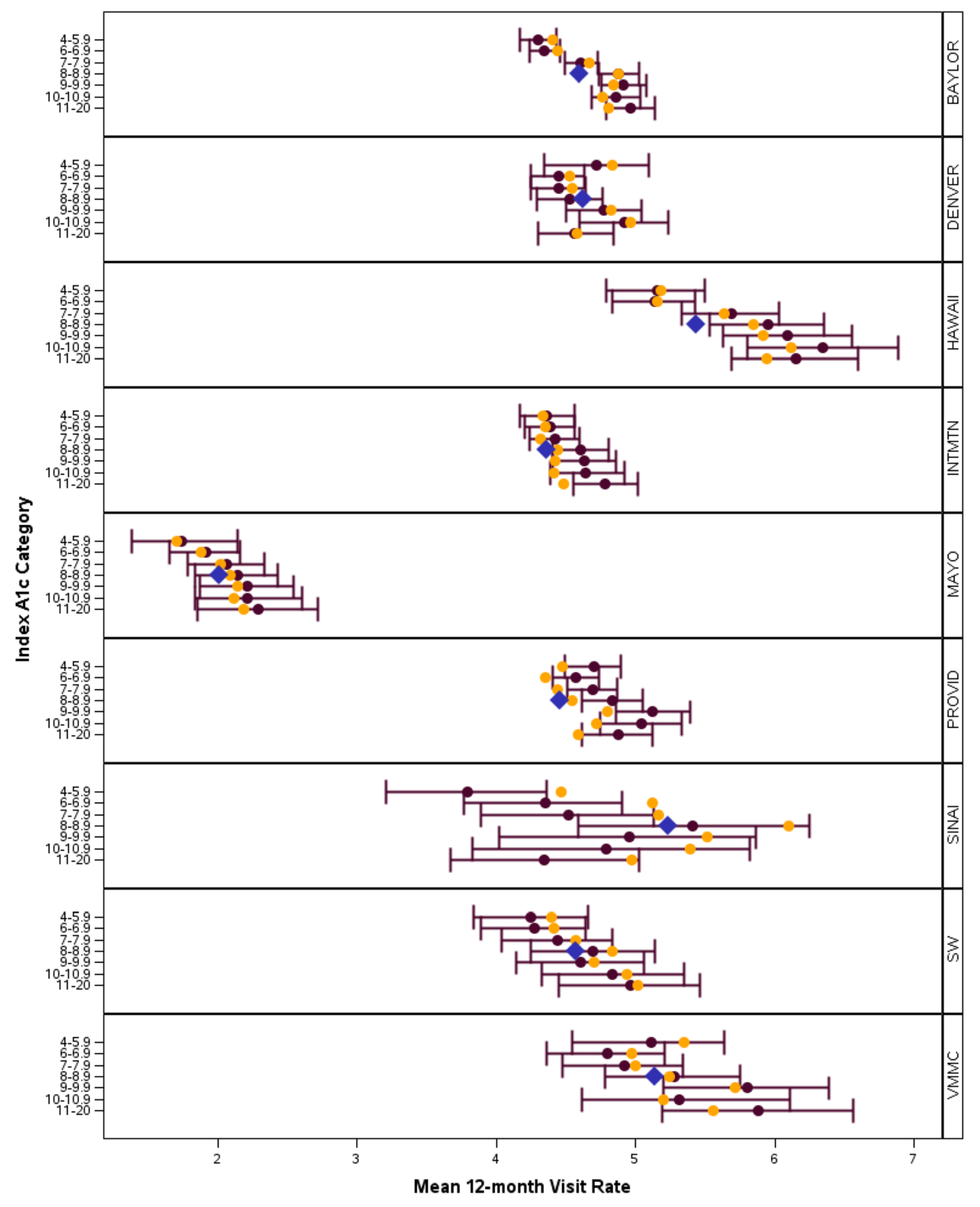

Unadjusted • Adjusted •

Unadjusted System Mean *

*Adjustment factors were age, race, sex, and low socioeconomic status.

Figure 1 Mean 12-month visit rate by organization and index A1c category, unadjusted and adjusted. 
Acknowledgments: Dr. Herndon, Ms. Gladders, Dr. Welch, and Mr. Belnap received support for this work during 2012-2016 from the Centers for Medicare \& Medicaid Services through a Health Care Innovation Grant awarded to the Trustees of Dartmouth College, High Value Healthcare Collaborative: Engaging Patients to Meet the Triple Aim Health Care Innovation Award (awardee number 1C1CMS331029PE). Dr. S. Mehta was supported by National Institutes of Health grant P3ODK036836.

Corresponding Author: M. Brooke Herndon, MD MS; Section of General Internal Medicine Dartmouth Hitchcock Medical Center and the Geisel School of Medicine, Lebanon, NH 03756, USA (e-mail: M. Brooke.Herndon@hitchcock.org).

\section{Compliance with Ethical Standards:}

Conflict of Interest: The authors declare that they do not have a conflict of interest.

\section{REFERENCES}

1. Petitti, D.B. and K. Grumbach, Variation in physicians' recommendations about revisit interval for three common conditions. Journal of Family Practice, 1993. 37(3): p. 235-40.

2. DeSalvo, K.B., et al., Predictors of variation in office visit interval assignment. International Journal for Quality in Health Care, 2003. 15(5): p. 399-405.

3. Pham, H.H., et al., Care patterns in Medicare and their implications for pay for performance. New England Journal of Medicine, 2007. 356(11): p. 1130-1139.

4. Yasaitis, L.C., J.P. Bynum, and J.S. Skinner, Association between physician supply, local practice norms, and outpatient visit rates. Medical Care, 2013. 51(6): p. 524-31.

5. Ganguli, I., J.H. Wasfy, and T.G. Ferris, What is the right number of clinic appointments?: Visit frequency and the accountable care organization. JAMA, 2015. 313(19): p. 1905-6.

6. Available from: https://www.highvaluehealthcare.org/.

Publisher's Note Springer Nature remains neutral with regard to jurisdictional claims in published maps and institutional affiliations. 